\title{
Dr John Ballantyne (1861-1923): perinatologist extraordinary of Edinburgh
}

\author{
Peter M Dunn
}

Few have contributed more to perinatal medicine than John William Ballantyne. He achieved distinction in gynaecology, obstetrics, midwifery, venereal disease, and neonatal medicine and pre-eminence in antenatal care, dysmorphology, fetal medicine, and perinatal pathology. Born in Midlothian in 1861 where his father kept a nursery garden, he graduated in Edinburgh in 1883 winning the Buchanan Scholarship which brought him under the influence of the Professor of Midwifery, A R Simpson. During the remaining 40 years of his life he occupied a variety of academic posts in Edinburgh ranging over the whole field of obstetrics, perinatal medicine, and pathology. In 1889 he married Miss Emily Mathew but there were no children and he was thus able to devote his phenomenal industry to the systematic and scientific study of the mother and her child from conception until the end of postpartum care. His knowledge was encyclopaedic and his writings prolific. Above all it was his remarkable vision and dogged persistence which led to the broadening of the disciplines of obstetrics and midwifery from being narrow specialties concerned with the technology of childbirth to the modern approach of positive maternal and child health through good antenatal care and the prevention of disease. ${ }^{1}$ Many honours and prizes came his way but he remained a simple, enthusiastic scholar and kindly practitioner whose prime aim was to be of service.

Among the five hundred or so of Ballantyne's published books and writings none is more significant than his great work called Antenatal Pathology and Hygiene: The Embryo and Foetus, published in two volumes in $1902-4 .^{2}$ In the preface he commented:

'In writing this book, I have honestly tried to avoid the four grounds of human ignorance set forth so long ago by Roger Bacon: trust in inadequate authority, the force of custom, the opinion of the inexperienced crowd, and the hiding of one's own ignorance with the parading of a superficial wisdom. I dare not hope that I have always succeeded; many times I ought perhaps to have said, "I do not know" where I have set forth high-sounding theories; but I have done what seemed at the time possible'.

Anyone interested in perinatal medicine should study this work. The subject is dealt with so comprehensively and Ballantyne was so

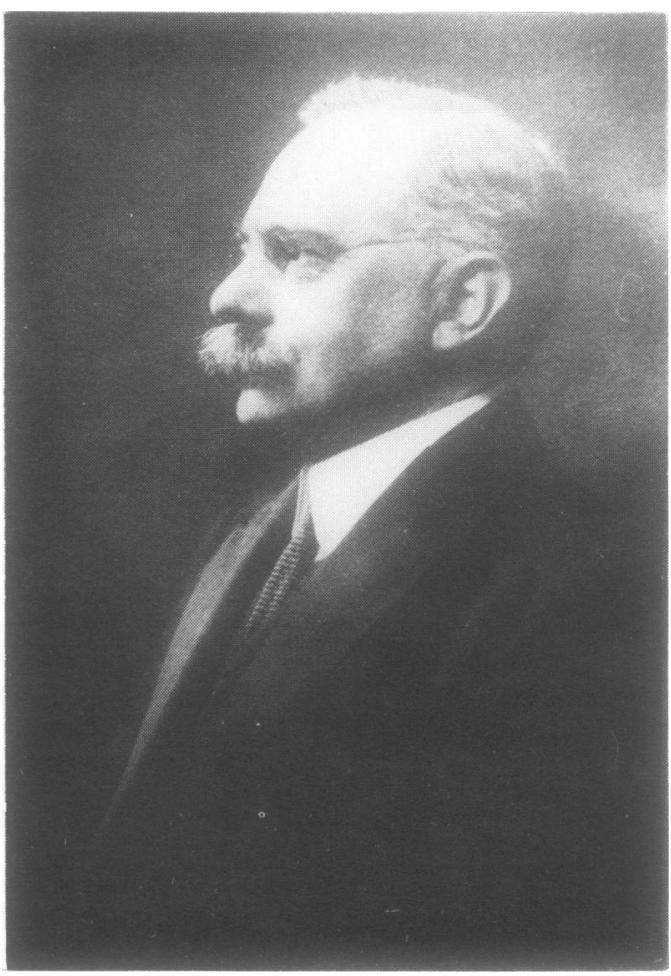

Dr fohn Ballantyne (1861-1923).

in advance of his time that there remains a great deal to excite the reader today. For example, the chapter on fetal poisoning includes sections on lead, mercury, phosphorus, arsenic, copper, sulphuric acid, coal gas, chloroform, ether, morphine, alcohol, and tobacco. His section in nicotism ends as follows:

'While there is much doubt, therefore, regarding the evil effect of nicotism in cutting short antenatal life, there seems to be no shadow of doubt there there is a very large infantile mortality in postnatal life among the offspring of women workers in tobacco. Possibly this may be due in part to the influence of the milk, but it is more probable that it is on account of congenital debility. Of course it is difficult to exclude the other possible causes of abortion, premature labour and infantile mortality (eg syphilis)'.

Then what chapter in a current text on fetal infection would include, as Ballantyne's does, accounts of fetal variola, vaccinia, measles, 
scarlet fever, erysipelas, parotitis, influenza, pertussis, relapsing fever, yellow fever, cholera, typhoid fever, malaria, tuberculosis, anthrax, syphilis, sepsis, cerebrospinal fever, and pneumonia!

On the maternofetal transmission of disease he wrote:

'The transmitted diseases of the foetus constitute the most interesting group of antenatal morbid states. Their interest depends, in the first place, upon the varied and intricate relations which are or may be established between the maternal and foetal organisms through them and as a result of them: in no physiological or pathological laboratory could more elaborate or instructive experiments be devised and carried through than are to be witnessed in the uterus, when the mother is the subject of a malady which is known to be transmissible. In the second place, their interest depends upon the possibilities of successful therapeutics which they present; when the cause of a disease is known, and when the diagnosis of its occurrence is not outside the bounds of possibility, the chances of successful treatment, preventive and curative, are much increased. To some extent it may be said that the etiology of the transmitted foetal diseases is within our knowledge, and their diagnosis not altogether outside our grasp; with perseverance and skill their treatment will yet be hopefully undertaken by the wellinformed physician'.

On the transmission of immunity he wrote:

'Just as diseases and drugs may be transmitted to the foetus in utero, so, it may be concluded, may immunities. At any rate, some evidence of this passage of immunising materials has been found in the vaccination of pregnant women ... The speculation may embrace also a reverse current of antilyssins and microbicidal principles from the foetus and the foetal part of the placenta to the mother'

The chapter containing the above quotation also contains sections on the hospitalisation of pregnant women, advice on the hygiene of pregnancy (including diet, occupation, exercise, and dress), the therapeutics of specific fetal problems and, finally, an account of germinal therapeutics, undoubtedly the forerunner of the preconception clinic of today. There was also 'A Plea for a Pre-maternity hospital or Home' of which the following is an extract:

'Since I published the plea for a pre-maternity hospital, I have become still more impressed with the need there is for the hospitalisation of the pregnant woman. The idea of a special hospital attached to each maternity may be chimerical, but there might at least be a ward or some beds set apart for the special treatment of diseases of pregnancy. That this would be beneficial for the maternity hospital itself, I do not doubt. Many of the fatal cases which occur in our maternities at present are due to complications of pregnancy (eg eclampsia, albuminuria) which have arisen before the admission of the patients. There can be no doubt, further, that a patient who has passed through a morbid pregnancy will be more liable to a bad labour than one in whom the changes of the wonderful gestation period have been accomplished in a physiological fashion'.

Ballantyne's plea was answered. A single bed was funded at the Royal Maternity Hospital in 1901. By 1917 it had grown, under his direction, into a whole antenatal department.

Space precludes more than a couple of the many vignettes it would be possible to cite from this great work. On the temperature of the fetus he comments:

'As it is not easy for the foetus in its secluded position in utero to lose heat, it may be concluded that its temperature will generally be above that of the mother. With a maternal temperature of $42^{\circ} \mathrm{C}$, or slightly more, the foetus will die; and even $40^{\circ} \mathrm{C}$ will become a danger to it, for the reason that it doubtless means a higher figure for the infant in utero than for the mother. Of course, the period of persistence of the high temperature must be taken into account'.

Then towards the end of a lengthy discussion of fetal respiration he remarked:

'Nature makes no leaps but prepares beforehand for the transitions of life and even for those of them which seem at first sight so abrupt as does the establishment of pulmonary respiration in the place of placental. She makes the necessary transitions easy. Truly, birth marks not a beginning but a stage in life's journey'.

In 1923, at the age of 61 , Ballantyne died suddenly after the removal of a gangrenous appendix. The four page obituary in the $B M \mathcal{F}$ attested to his outstanding personal qualities as well as to his amazing scientific contributions. ${ }^{3}$ In his own life he certainly lived up to his own stated aim for medicine:

'The goal of the medical man's ambition and the limits of his usefulness to his patient are not reached when the diagnosis of the malady from which the latter is suffering has been made. The most exact diagnosis is unsatisfactory if unaccompanied by effective treatment. The end and aim of all medical practice is prevention; and failing that, cure; and, failing, that, amelioration'.

1 Ballantyne JW. The new midwifery: preventive and reparative obstetrics. BMF 1923;i:617-21.

2 Ballantyne JW. Antenatal pathology and hygiene: the embryo and the foetus. 2 Vols. Edinburgh: William Green and and the foetus. 2 Vols.

3 Ballantyne JW. Obituary. BMF 1923;i:213-6. 